A-rkivoc

Free to Authors and Readers
A Platinum Open Access Journal for Organic Chemistry
Paper

Arkivoc 2021, part iii, 13-24

\title{
Synthesis of new heterocycle-based selenoamides as potent cytotoxic agents
}

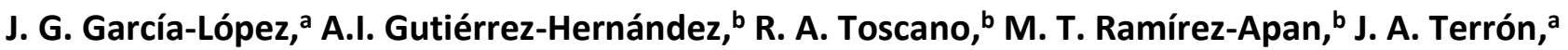 M. C. Ortega-Alfaro, ${ }^{\mathrm{C}}$ and J. G. López-Cortés*b}

${ }^{a}$ Departamento de Farmacología, Centro de Investigaciones y Estudios Avanzados CINVESTAV-IPN, Av. IPN, Gustavo A. Madero, CP 07360, Cd. Mx. México

bInstituto de Química, Universidad Nacional Autónoma de México, Circuito Exterior, Ciudad Universitaria, Coyoacán, CP 04510 Cd. Mx. Mexico

'Instituto de Ciencias Nucleares, Universidad Nacional Autónoma de México, Circuito Exterior, Ciudad Universitaria, Coyoacán, C.P. 04510 Cd. Mx. Mexico

Email:jglcvdw@unam.mx

\section{In honor of Professor Lanny Liebeskind}

\section{Received 07-10-2020}

Accepted 09-03-2020

Published on line $09-15-2020$

\section{Abstract}

We report the synthesis of a new series of aryl- and heteroaryl (hydroxy)ethyl selenoamides, in a two-step, one-pot sequence based on the aminolysis/selenative demetalation of Fischer ethoxycarbene complexes, in good to excellent global yields, as small cytotoxic molecules. The molecular structure of a 2-thienyl based selenoamide was confirmed by single-crystal X-Ray diffraction analysis. In vitro analysis against different human cancer (HCT-15, U251 and PC-3) and human T-lymphocyte (MT2) cell lines revealed that the 2-thienyl based selenoamide can be considered a potent and selective compound against the human prostatic adenocarcinoma (PC-3) cell line with an $\mathrm{IC}_{50}$ value of $14.5 \mu \mathrm{M}$.
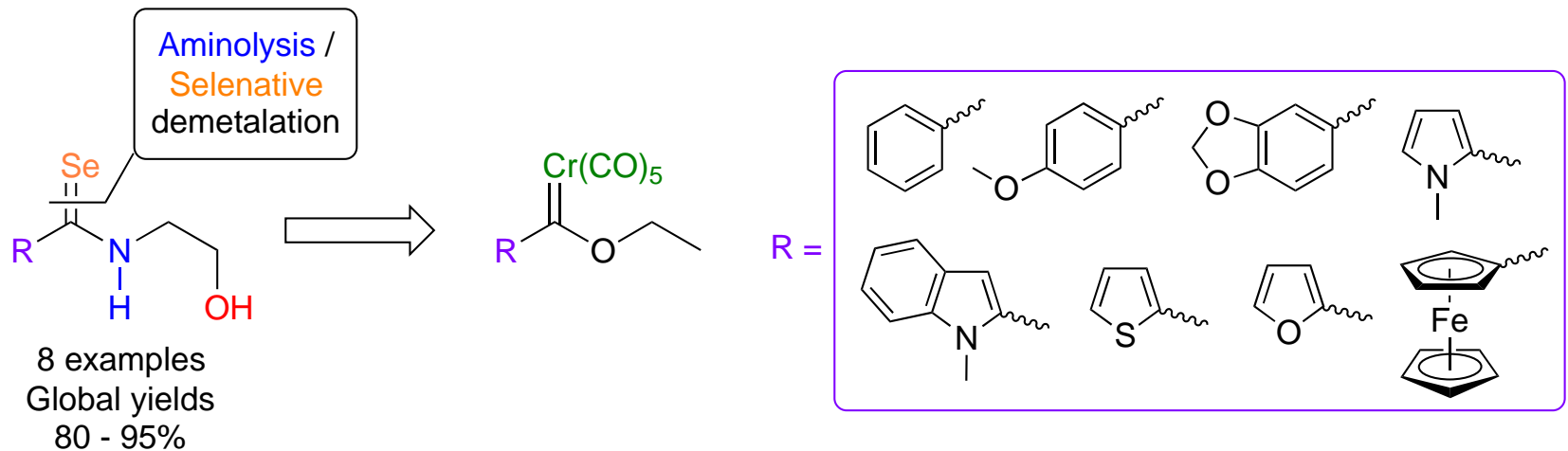

Keywords: Fischer carbene complexes, demetalation, selenoamides, selenium, cytotoxic activity 


\section{Introduction}

Currently, selenium is attracting considerable attention apart from its role as a micronutrient, since several organoselenium compounds have displayed a tremendous variety of bioactivities, ranging from antioxidant enzyme mimics, ${ }^{1}$ to neuroprotective, ${ }^{2}$ antibacterial, ${ }^{3}$ antiparasitic, ${ }^{4}$ anticonvulsant, ${ }^{5}$ antiviral ${ }^{6}$ and anticancer activity, ${ }^{7}$ among others. ${ }^{8-12} \mathrm{~A}$ wide spectrum of organoselenium compounds has been tested against different human cancer cell lines, showing promising cell growth inhibition. In this context, our research group developed the synthesis of a ferrocene(hydroxy)alkylselenoamides family, ${ }^{13}$ that act as cytotoxic agents against different human cancer cell lines, especially on MCF-7, HCT-15, and U251, exerting superior activities than those displayed by marketed drugs tamoxifen and cisplatin. This behavior has placed these compounds in an emerging and very promising class of ferrocene antitumor agents, ${ }^{14-16}$ allowing the establishment of some structural key fragments for synthesizing new potentially cytotoxic selenoamides.

Considering the precedent results obtained for leader ferrocenyl selenoamide, we decided to modify the structure at the aromatic ring position of this compound, based on the assumption that this substituent could enhance the bioactivity by promoting the selectivity or potency of these new compounds. For instance, we chose diverse aromatic rings, including $p$-methoxyphenyl and methylenedioxyphenyl, and different heterocycles like $\mathrm{N}$-methylpyrrol-2-yl, $\mathrm{N}$-methylindol-2-yl, thien-2-yl and furan-2-yl. These rings are frequently occurring motifs in drug-like molecules (Figure 1). ${ }^{17}$

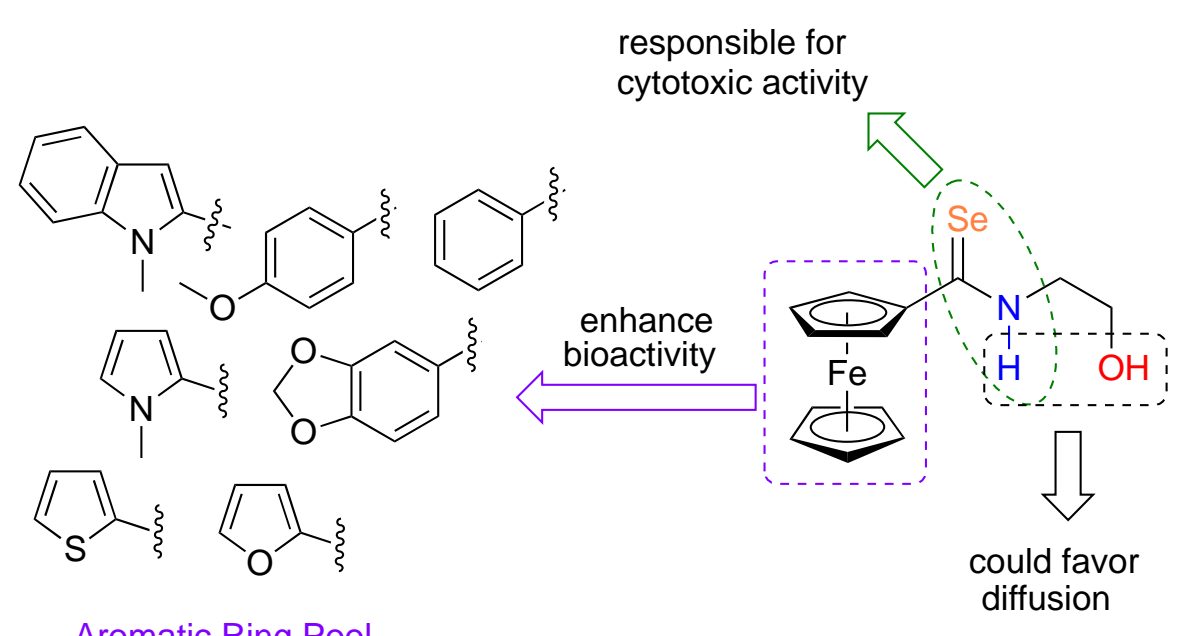

Figure 1. Design for the obtainment of potentially cytotoxic arylselenoamides.

The conversion of carbonyl groups into the corresponding selenocarbonyl compounds through treatment with various selenating reagents possessing reactive metal-selenium bonds ${ }^{20-24}$ or Woolins reagent ${ }^{25-26}$ remain as the most accessible approaches to obtain this kind of compound, despite the difficulty of preparing and using such selenating reagents. As an alternative, we recently developed a methodology that uses elemental selenium in combination with $\mathrm{NaBH}_{4}$ as the reagent to introduce selenium functionalities into organometallic compounds in mild reaction conditions. ${ }^{13}$

Continuing with our studies related to the chemistry of selenocarbonyl compounds, we describe here the synthesis and study of the cytotoxic properties of new aryl and heteroaryl selenoamides, with the aim to obtain new potent and selective organoselenium compounds. We used as key starting material a family of 
Fischer carbene complexes that allows the easy introduction of a selenocarbonyl functionality, in a two-step, one pot synthesis.

\section{Results and Discussion}

Initially, we prepared the Fischer ethoxycarbene complexes (1a-h) (Table 1), using improved methods previously reported by our research group and others, achieving good to high yields. ${ }^{18-19}$ These compounds were characterized by conventional spectroscopic techniques and the data obtained agreed with those reported in literature. ${ }^{13-19}$ The complex $1 \mathrm{c}$ is new and exhibits the characteristic absorption bands around 2057 and $1905 \mathrm{~cm}^{-1}$ assigned to $\mathrm{M}-\mathrm{CO}$. From the ${ }^{13} \mathrm{C}$ NMR spectrum, we identified a signal at $339.8 \mathrm{ppm}$ assigned to $\mathrm{C}=\mathrm{Cr}$. We also observed two signals around 223.8 and $216.7 \mathrm{ppm}$ assigned to $\left(\mathrm{CrCO}_{\mathrm{ax}}\right)$ and $\left(\mathrm{CrCO}_{\mathrm{eq}}\right)$, respectively.

After preparing the ethoxycarbene complexes, these compounds were exposed to an aminolysis reaction using ethanolamine, affording the corresponding Fischer aminocarbene complexes (2a-h) in good yields (Table 1). The new carbene complexes showed in their infrared spectra bands around 2054, 1974 and $1911 \mathrm{~cm}^{-1}$ characteristic of $\mathrm{Cr}$-CO.

In all cases, a molecular ion was observed in the mass spectra (FAB+). In the ${ }^{13} \mathrm{C} N M R$ spectra, we observed a characteristic signal around $\delta 270 \mathrm{ppm}$ assigned to carbenic carbon as well as signals around $\delta 210-225 \mathrm{ppm}$ for $\mathbf{C r}$-CO. All the aminocarbene complexes, with the exception of $\mathbf{2 e}$ and $\mathbf{2} \mathbf{h}$, were obtained as a mixture of non-separable $E / Z$ geometric stereoisomers. The ${ }^{1} \mathrm{H}$ NMR spectra displayed two sets of signals, the most easily seen being those assigned to the $\mathrm{NH}$ group, with a shift around $9.4 \mathrm{ppm}$ for the $E$ stereoisomer and around 9.0 ppm for the $Z$ stereoisomer. In most cases, the $E$ stereoisomer is the major species, which agrees with the behavior reported for similar carbene complexes. ${ }^{28,32-33}$ However, for $\mathbf{2 h}$, the $Z$ stereoisomer is the only species, ${ }^{13}$ as result of the steric interaction between the ferrocenyl group and the hydroxyalkyl chain.

With the aminocarbene complexes in hand, we carried out their selenative demetalation to obtain the arylselenoamides (3a-h), using the protocol earlier developed by our group for synthesizing ferrocenyl selenoamides. ${ }^{13,} 31$ This procedure provided the new arylselenoamides as yellow-red solids, in 15 to 45 min, depending on the ethoxy carbene complex used as precursor (Table S1, SI). To increase the global yields of these compounds, we attempted a two-step, one-pot synthesis based on the aminolysis-demetalation reaction as a key strategy. This improved the global yields of the selenoamides by up to $80 \%$ starting from the respective commercially available aromatic ring compound (Scheme 1). No selenols were detected in the reaction mixture and the persistence of the $\mathrm{OH}$ functional group in all the products obtained, confirmed the selectivity and tolerance of the reagent formed by the mixture $\mathrm{Se} / \mathrm{NaBH}_{4}$, providing a useful method for obtaining selenocarbonyl derivatives in mild reaction conditions via Fischer carbene complexes. 
Table 1. Synthesis of ethoxycarbene complexes (1a-h) and aminocarbene complexes (2a-h)

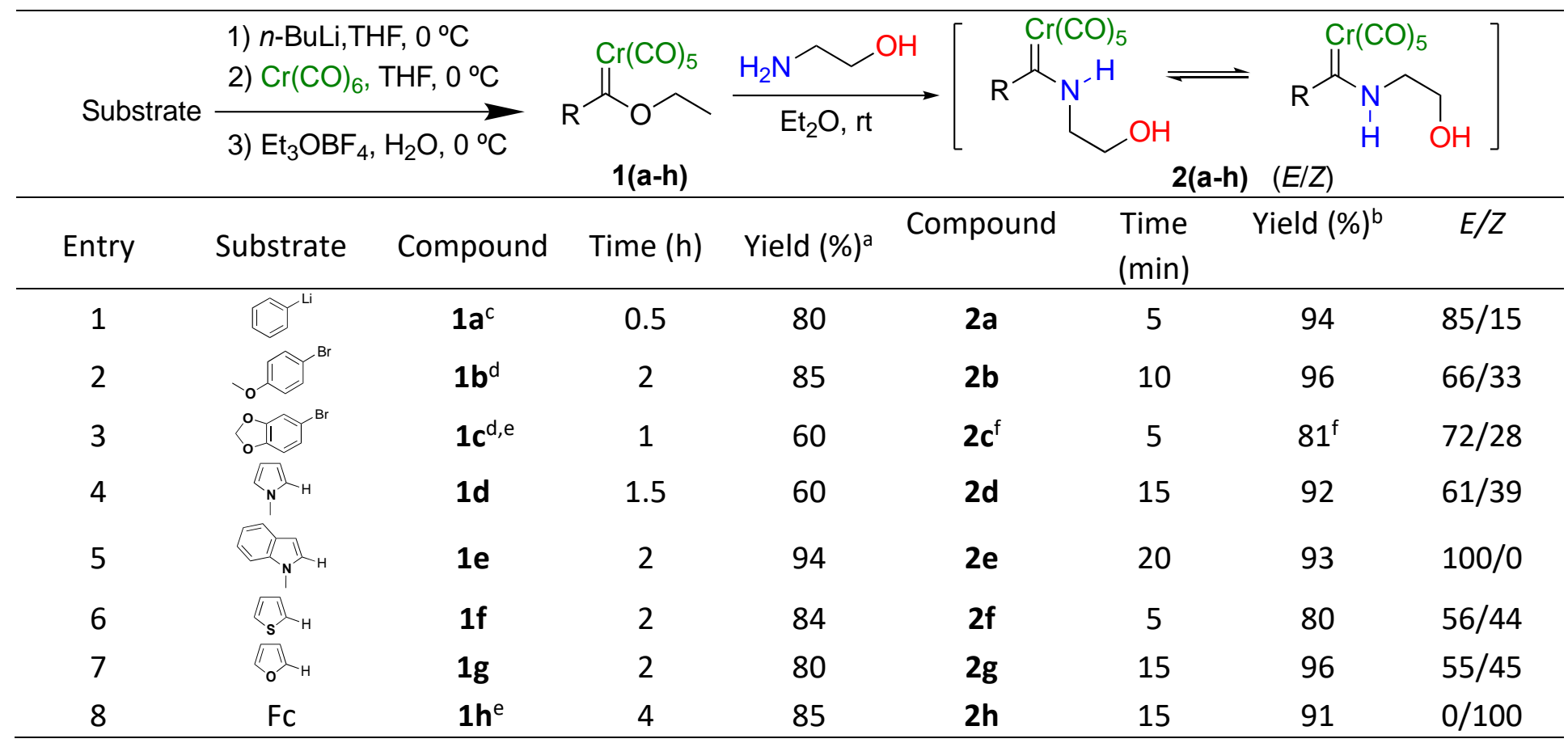

${ }^{a}$ Yields obtained of pure product after flash column chromatography purification on $\mathrm{SiO}_{2} .{ }^{\mathrm{b}}$ The yield is given for the mixture of $E / Z$ conformers. ' Phenyllithium (available commercially) was used as starting substrate, going directly to step $2 .{ }^{\mathrm{d}}$ The formation of these lithium derivatives was conducted at $-78{ }^{\circ} \mathrm{C} .{ }^{\mathrm{e}} t$-BuLi was used as base. ${ }^{f}$ Unstable compound in solution.

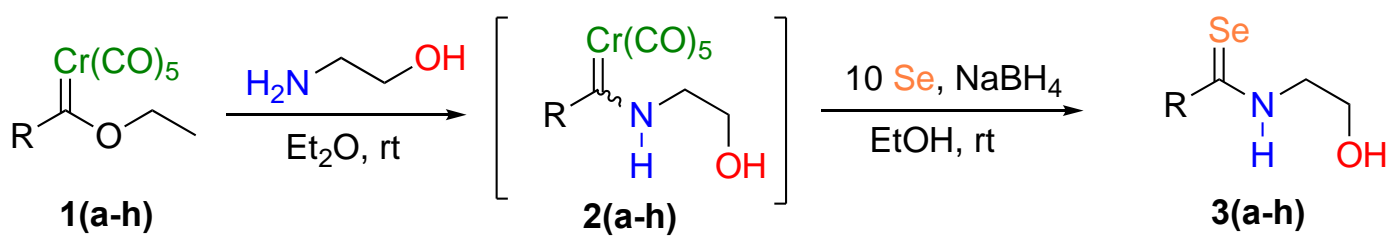

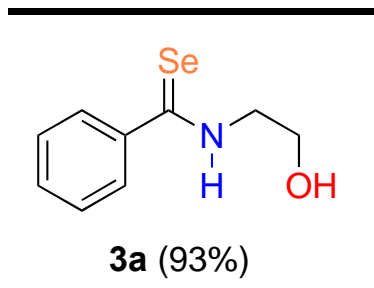

$(74 \%)^{\mathrm{a}}$

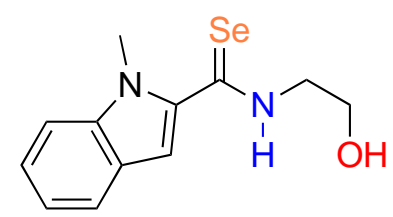

3e $(80 \%)$

$(75 \%)^{a}$<smiles>COc1ccc(C(=[Se])NCCO)cc1</smiles>

3b (95\%)

$(80 \%)^{a}$<smiles>OCCNC(=[Se])c1cccs1</smiles>

$3 \mathbf{f}(91 \%)$

$(76 \%)^{a}$<smiles>OCCNC(=[Se])c1ccc2c(c1)OCO2</smiles>

$(54 \%)^{a}$<smiles>OCCNC(=[Se])c1ccco1</smiles>

3 g (92\%)

$(74 \%)^{a}$<smiles>Cn1cccc1C(=[Se])NCCO</smiles>

3d (90\%) $(54 \%)^{a}$

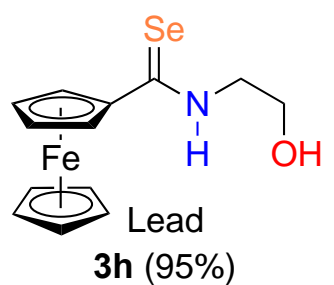

$(81 \%)^{a}$

Scheme 1. Synthesis of aryl selenoamides in one-pot, two-step conditions. ${ }^{a}$ Global yield calculated from the corresponding aryl (or heteroaryl) substrate. 
The arylselenoamides were characterized using conventional spectroscopic techniques. They exhibited in infrared spectra bands around 1440, 1090 and $650 \mathrm{~cm}^{-1}$. These bands are characteristic of a mixed vibrational mode assigned to the fragment $\mathrm{N}-\mathrm{C}=\mathrm{Se}$, where the stretching vibration $v(\mathrm{C}=\mathrm{Se})$ is strongly coupled to $v(\mathrm{C}-\mathrm{N})$. $^{34-}$ 35 In all cases, the mass spectrum (EI) of each selenocarbonyl displayed a molecular ion in concordance with the molecular formula for each compound and confirmed the complete removal of metallic fragment $\left[\mathrm{Cr}(\mathrm{CO})_{5}\right]$.

The ${ }^{1} \mathrm{H}$ NMR spectra of these compounds show the signal of selenoamide proton shifted to low-field around 89 ppm revealing a possible intramolecular interaction via a hydrogen bond between $\mathrm{N}-\mathrm{H} \cdots \mathrm{OH}$. This behavior is more evident in the case of compound 3c, which shows both signals more shifted to high frequencies compared to those displayed for the other members of this series of compounds. Likewise, the ${ }^{13} \mathrm{C} N M R$ spectra showed a signal around $\delta 203 \mathrm{ppm}$ assigned to $\mathrm{C}=\mathrm{Se}$ for benzene based selenoamides, and high-field shifts around $\delta 185$ ppm for their heterocyclic analogues. The purity of selenoamides obtained was certified using different analytical techniques. ${ }^{36}$

In addition, we confirmed the structural arrangement of the thienyl based selenoamide $\mathbf{3 f}^{37}$ through singlecrystal X-ray diffraction analysis (Figure 2). This study revealed that selenocarbonyl moiety is directly bonded to the $\alpha$ position of the thiophene ring; the sum of bond angles around $C(6)\left(\Sigma=359.98^{\circ}\right)$ indicates the trigonal geometry of this group. The $\mathrm{C}=\mathrm{Se}$ double bond distance [Se(1)-C(6) $1.836(2) \AA]$ is quite similar to other reported selenoamides; nevertheless, the $\mathrm{N}(1)-\mathrm{C}(6) 1.321(2) \AA$ bond distance is relatively longer. Additionally, in the solid-state packing, we observe an intermolecular hydrogen bond $\mathrm{N}-\mathrm{H}----\mathrm{O}$, demonstrating the capability of the aminoalcohol fragment to favor this kind of interactions, which may be a significant influence in biological systems. ${ }^{38-40}$

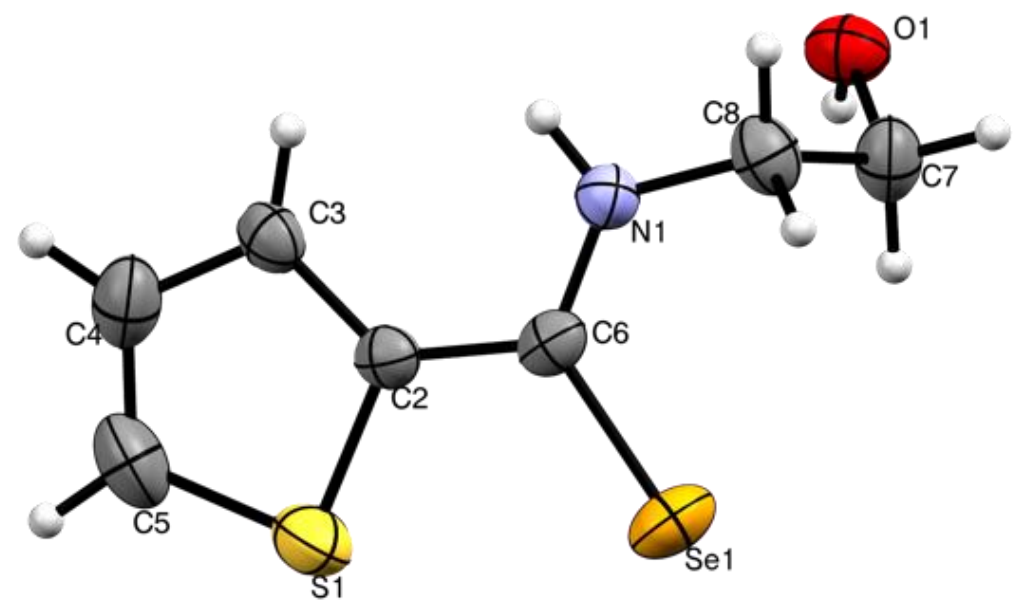

Figure 2. ORTEP representation of selenoamide $\mathbf{3 f}$. Ellipsoids are shown at $30 \%$ probability level. Selected bond lengths $[\AA]$ and angles [deg]: $\mathrm{Se}(1)-C(6) 1.836(3), N(1)-C(6) 1.321(3), C(6)-C(2) 1.453(3) ; C(2)-C(6)-S e(1)$ $120.28(16), N(1)-C(6)-S e(1) 122.97(17), N(1)-C(6)-C(2) 116.73(19)$.

Concerning the selenating process, it could occur in two consecutive steps: first the selenium reacts with sodium borohydride forming the diselenide $\mathbf{A}$ - similar adducts have been proposed as intermediates in the formation of sulfides and polysulfides when elemental sulfur is used as the chalcogen (Scheme 2). ${ }^{41-42}$ Once formed, A reacts with the electrophilic Fischer carbene forming the intermediate $\mathbf{B}$. This species loses the 
metallic fragment $\left[\mathrm{Cr}(\mathrm{CO})_{5}\right]$ and $\left(\mathrm{H}_{2} \mathrm{BSe}^{-}\right)$, affording the corresponding selenoamide. In an attempt to obtain insight on the plausible pathway of this transformation, we conducted two additional experiments. When this reaction as conducted in stochiometric conditions, we only recovered the selenoamide coordinated with $\left[\mathrm{Cr}(\mathrm{CO})_{5}\right]$ in low yields, which implies that the 10 -fold excess of selenating reagent $\left(\mathrm{Se} / \mathrm{NaBH}_{4}\right)$ favors the complete removal of chromium fragment. On the other hand, when we used benzyl bromide in the place of the carbene complex, we obtained quantitively the corresponding benzyl diselenide. This result confirms the identity and the nucleophilic character of adduct A. Likewise, after the work-up of the reaction, we observed the formation of a black powder, presumably due to the disproportion of $\mathbf{C}$ affording black selenium.

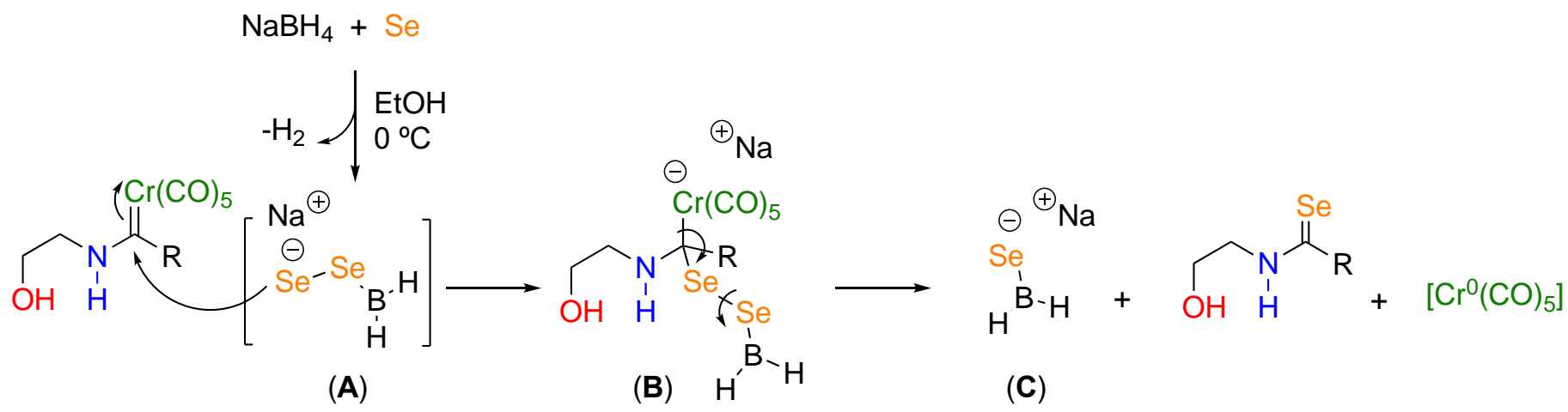

Scheme 2. Proposed pathway to obtain aryselenoamides using $\mathrm{Se} / \mathrm{NaBH}_{4}$.

We tested the cytotoxicity of the selenocarbonyl compounds $\mathbf{3}(\mathbf{a}-\mathbf{h})$ in different cancer cell lines, including HCT-15 (human colorectal adenocarcinoma), U251 (human glioblastoma), PC-3 (human prostatic adenocarcinoma), MCF-7 (human mammary adenocarcinoma), K562 (human chronic myelogenous leukemia), SKLU-1 (human lung adenocarcinoma), which was determined by using the protein-binding dye Sulforhodamine B (SRB) assay in microculture to determine cell growth. ${ }^{43-44}$

The initial screening data listed in Table S2 show a substantial difference in the bioactivity displayed by these new selenoamides in comparison with the ferrocenylselenoamide Lead ( $3 \mathrm{~h})$, which possesses a really good activity towards HCT15, U251 and specially against MCF-7. ${ }^{13}$ Compounds $\mathbf{3}(\mathbf{a}-\mathbf{g})$ display good activity towards HCT-15, U251 and particularly against PC-3 human cancer cell lines. Comparing the percentage of inhibition of selenoamides $\mathbf{3}(\mathbf{a}-\mathbf{g})$ in these cell lines, we observed good results for $\mathbf{3 b}, \mathbf{3 c}, \mathbf{3 e}$ and $\mathbf{3 f}$, with values greater than $65 \%$ of cell growth inhibition (Table S3, entries 2, 3, 5 and 6).

To correlate the effect of the aromatic ring on the structure of these selenoamides with their biological activity, we chose the HCT-15, U251 and PC-3 cancer cell lines. Thus, the IC 50 values against the selected human cancer cell lines were determined and compared with the ferrocenyl selenoamide Lead ( $3 \mathrm{~h}$ ) and two well-known commercial drugs, etoposide and cisplatin as references. Likewise, to know the cytotoxic selectivity, we also determined the $\mathrm{IC}_{50}$ values against MT2 cells (human T-lymphocytes). The results listed in Table 2 show that the aromatic fragments included in this series of compounds do not improve the inhibitory activity of ferrocenyl selenoamide (3h, Lead) in cell lines HCT-15 and U251. Only the selenoamide 3a exhibited activity close to cisplatin in HCT-15 (Table 2, entries 1 and 9). Comparing the IC 50 obtained in HCT-15 for $3 \mathbf{h}$ and etoposide, the former exhibits a better biological response (entries 8 and 10).

On the other hand, when we compare the biological response obtained in the PC-3 cell line, we observed that selenoamides $\mathbf{3 a}, \mathbf{3 d}, \mathbf{3} \mathbf{f}$ and $\mathbf{3 h}$ exhibit a better cytotoxic activity than cisplatin and etoposide, with $\mathrm{IC}_{50}$ values 
between 14-17 $\mu \mathrm{M}$ (Table 2, entries 1, 4, 6 and 8-10). These results are particularly interesting, showing that the incorporation of a 2-thienyl fragment, instead of the ferrocenyl motif, improves the cytotoxic activity of the selenoamide (Table 2, entries 6 and 8). Although the nature of these fragments - aromatic rings with electron-donor properties - we consider that it is not only electronic effects playing a role in the biological response. Both steric hindrance and $\pi$-stacking interactions could facilitate a better recognition of the biological target responsible of the cytotoxic response.

Table 2. $I C_{50}(\mu \mathrm{M})$ obtained for $\mathbf{3}(\mathrm{a}-\mathrm{h})$, cisplatin and etoposide in different cell lines ${ }^{\mathrm{a}}$

\begin{tabular}{cccccc}
\hline Entry & Compound & HCT15 & U251 & PC-3 & MT2 \\
\hline 1 & 3a & $16.6 \pm 1.4$ & $15.0 \pm 0.5$ & $17.01 \pm 0.9$ & $95.5 \pm 3.3$ \\
2 & 3b & $109 \pm 2.1$ & $19.0 \pm 0.1$ & $37.3 \pm 2.5$ & $>100$ \\
3 & 3c & $17.8 \pm 1.2$ & $19.4 \pm 1.3$ & $22.4 \pm 1.8$ & $88.7 \pm 1.0$ \\
4 & 3d & $51.1 \pm 0.9$ & $19.9 \pm 1.1$ & $17.4 \pm 1.6$ & $98.7 \pm 2.3$ \\
5 & 3e & $37.55 \pm 2.58$ & $26.84 \pm 1.6$ & $33.76 \pm 3.1$ & $105.5 \pm 3.8$ \\
6 & $\mathbf{3 f}$ & $42.8 \pm 4.0$ & $26.4 \pm 1.1$ & $14.5 \pm 0.07$ & $>100$ \\
7 & $3 g$ & $50.88 \pm 4.1$ & $31.03 \pm 1.7$ & $44.15 \pm 2.6$ & $>100$ \\
8 & 3h (Lead) & $4.48 \pm 0.09$ & $7.24 \pm 0.5$ & $16.0 \pm 0.2$ & $>100$ \\
9 & Cisplatin & $13.5 \pm 0.7$ & $9.5 \pm 0.7$ & $20.3 \pm 1.2$ & $9.72 \pm 1.12$ \\
10 & Etoposide & $8.4 \pm 0.7$ & $2.2 \pm 0.4$ & $28.64 \pm 2.7$ & -- \\
\hline
\end{tabular}

${ }^{\mathrm{a}} \mathrm{IC}_{50}(\mu \mathrm{M})$ determined at $48 \mathrm{~h}$ in $\mathrm{EtOH}$.

Finally, with the aim of knowing the cytotoxic behavior of compounds $\mathbf{3}(\mathbf{a}-\mathbf{h})$ in normal cells, the selenoamides were also tested against human T-lymphocytes (MT2) cells. In general, IC 50 values determined for non-cancer MT2 cells are higher than those found in cancer cell lines (Table 2). On the contrary, cisplatin was shown to be more cytotoxic against MT2 cells. These results reveal a high selectivity towards cancer cell lines and allow us to consider this family of molecules as good candidates for further chemical variations, focused on improving their pharmacological behavior.

\section{Conclusions}

In conclusion, we have optimized the synthesis of novel aryl and heteroaryl selenoamides through a two-step sequence in one-pot based on the aminolysis/selenative demetalation reactions of Fischer ethoxycarbene complexes, in excellent global yields to obtain cytotoxic small molecules. The synthetic methodology is simple, efficient, and robust, allowing the introduction of several structural motifs.

The biological assays revealed that varying the aromatic ring directly attached to selenoamide moiety resulted in diverse cytotoxic activities IC 50 towards HCT-15, U251 and PC-3 human cancer cell lines as compared with ferrocene selenoamide lead and the well-known reference marketed drugs, cisplatin and etoposide.

This evaluation showed that modifications in the nature of the aromatic rings can improve the biological response of these organoselenium compounds. The $\mathrm{IC}_{50}$ values determined for MT2 cells were higher than those for HCT-15, U251 and PC-3 cell lines, which indicates a very good selectivity towards human cancer cells. Likewise, these results along with the structural modifications, indicate that these selenocarbonyl compounds 
are good candidates for conducting a further QSAR model to reach an in-depth understanding of their pharmacological response behavior.

\section{Experimental Section}

General. Materials and Instruments. THF and diethyl ether were distilled from sodium/benzophenone under a nitrogen atmosphere. All reagents and solvents were obtained from commercial suppliers and used without further purification. All compounds were characterized by IR spectra, recorded on a Bruker Tensor 27 spectrophotometer, by $\mathrm{KBr}$ or film techniques, and all data are expressed in wave numbers $\left(\mathrm{cm}^{-1}\right)$. Melting points were obtained on a Melt-Temp II apparatus and are uncorrected. NMR spectra were measured with a JEOL Eclipse +300 and Bruker Avance III 300, using $\mathrm{CDCl}_{3}$ and $\mathrm{CD}_{3} \mathrm{CN}$ as solvents. Chemical shifts are in ppm ( $\delta$ ), relative to TMS. The MS-EI were obtained on a JEOL JEM-AX505HA using $70 \mathrm{eV}$ as ionization energy and for MS-FAB on a JEOL SX 102A. All tested compounds synthesized are more than $95 \%$ pure, analyzed using HPLC HP 1100 with diode-array detector.

Synthesis of Fischer type-carbene chromium( 0 ) complexes $\mathbf{1}(\mathrm{a}-\mathrm{h})$. The preparation of these complexes was carried out using a slight modification of the methodology previously described elsewhere. ${ }^{13-19}$ To a solution of the corresponding aryl substrate $(8 \mathrm{mmol})$ in anhydrous THF $(10 \mathrm{~mL})$ under argon atmosphere was added at 0 ${ }^{\circ} \mathrm{C}$, a solution of $n \mathrm{BuLi}(8.2 \mathrm{mmol})$. The reaction mixture was stirred at rt for 20 to $60 \mathrm{~min}$ and then transferred by cannula to a suspension of $\mathrm{Cr}(\mathrm{CO})_{6}(1.74 \mathrm{~g}, 8 \mathrm{mmol})$ in THF $(20 \mathrm{~mL})$, the mixture was then stirred for the time specified in Table 1, at rt. The solvent was removed under vacuum and to the residue was added the mixture obtained from triethyloxonium tetrafluoroborate $(2 \mathrm{~g}, 10 \mathrm{mmol})$ added to ice/water (ca. $20 \mathrm{~g})$. The organic phase was washed with a saturated solution of $\mathrm{NaHCO}_{3}$ and then with brine. The organic phase was dried with anhydrous $\mathrm{Na}_{2} \mathrm{SO}_{4}$ and the solvent was evaporated under vacuum. The mixture was purified by chromatography on silica gel or alumina using hexane as eluent. Compounds $\mathbf{1 a}, \mathbf{1 b}, \mathbf{1 c}, \mathbf{1 d}, \mathbf{1 f}, \mathbf{1 g}$ and $\mathbf{1 h}$ are known and their spectroscopic data matched well with that already described in the literature. ${ }^{13,}$ 27-31

\section{Synthesis of selenoamides ( $3 a-h)$ in one-pot two-step conditions}

(a) Synthesis of aryl Fischer hydroxyethylamino carbene complexes 2. To a solution of the corresponding Fischer ethoxycarbene complex $1(1 \mathrm{mmol})$ in $10 \mathrm{~mL}$ of anhydrous $\mathrm{Et}_{2} \mathrm{O}$ under $\mathrm{N}_{2}$ atmosphere was added ethanolamine $(2.1 \mathrm{mmol})$. The reaction mixture was stirred at $\mathrm{rt}$ for 5 to $20 \mathrm{~min}$ and then diluted with water $(10 \mathrm{~mL})$. The organic phase was separated and dried with anhydrous $\mathrm{Na}_{2} \mathrm{SO}_{4}$, and the solvent was evaporated in vacuum. The crude product was used for the next reaction step.

(b) Synthesis of selenoamides 3(a-h). Preparation of selenating agent. To a solution of of $\mathrm{NaBH}_{4}\left(0.01 \mathrm{~mol}^{2}\right.$ in $\mathrm{EtOH}(10 \mathrm{~mL})$ was added of powdered selenium $(0.01 \mathrm{~mol})$, and the mixture was vigorously stirred at $\mathrm{rt}$ for 30 min under $\mathrm{N}_{2}$. The selenating agent was then added to a solution of the corresponding amino carbene complex 2, previously obtained, in $\mathrm{EtOH}(5 \mathrm{~mL})$, under $\mathrm{N}_{2}$. The reaction was monitored by TLC on silica-gel. After the reaction was completed, the solvent was evaporated under vacuum, the residual mixture was dissolved in distilled water and the product was extracted with $\mathrm{CH}_{2} \mathrm{Cl}_{2}$ and then dried with anhydrous $\mathrm{Na}_{2} \mathrm{SO}_{4}$. After the evaporation of the solvent, the resultant mixture was purified by silica-gel column using hexane $/ \mathrm{CH}_{2} \mathrm{Cl}_{2}(1: 1)$ as eluent. 
Determination of purity. The purity of the final products is close to 95-99\% and was determined using 60:40 and 40:60 (hexane/ammonium acetate) as the mobile phase with a flow rate of $0.2 \mathrm{~mL} / \mathrm{min}$ on a Zorbax Bonus RP column (3.5 $\mu \mathrm{m}, 2.1 \times 100 \mathrm{~mm}$, Agilent).

X-ray crystallography. Suitable X-ray quality crystals of $\mathbf{3 f}$ were grown by slow evaporation of a $\mathrm{CHCl}_{3}$ solution at rt. A crystal of $\mathbf{3 f}$ was mounted on a glass fiber at room temperature, then placed on a Bruker Smart Apex CCD diffractometer, equipped with Mo KR radiation; decay was negligible in both cases. Systematic absences and intensity statistics were used in space group determination. The structure was solved using direct methods. ${ }^{45}$ Anisotropic structure refinements were achieved using full matrix, least-squares technique on all non-hydrogen atoms. All hydrogen atoms were placed in idealized positions, based on hybridization, with isotropic thermal parameters fixed at 1.2 times the value of the attached atom. Structure solution and refinement were per-formed using SHELXTL V6.10. ${ }^{46}$

\section{Acknowledgements}

The authors appreciate the technical assistance of Rocío Patiño, Antonio Nieto-Camacho, Carmen Márquez, Hector Rios and Javier Pérez. They also wish to thank the DGAPA-PAPIIT IN205014 and CONACYT 285722 projects.

\section{Supplementary Material}

Spectroscopic data of all the compounds obtained, NMR and HR-Mass spectra for new compounds and the methodology for cytotoxic studies are included in the SI. Details of crystallographic data collected for compound $\mathbf{3 f}^{37}$ are provided in SI. Likewise, CCDC-1015044 (3f) contains the supplementary crystallographic data for this paper. These data can be obtained free of charge from The Cambridge Crystallographic Data Centre via www.ccdc.ac.uk/data_request/cif.

\section{References}

1. Wolters, L. P.; Orian, L. Curr. Org. Chem. 2016, 20, 189.

https://doi.org/10.2174/1385272819666150724233655

2. Pinton, S.; Brüning, C. A.; Sartori Oliveira, C. E.; Prigol, M.; Nogueira, C. W. J. Nutr. Biochem. 2013, 24, 311.

https://doi.org/10.1016/i.jnutbio.2012.06.012

3. Thangamani, S.; Younis, W.; Seleem, M. N. Sci. Rep. 2015, 5, 11596.

https://doi.org/10.1038/srep11596

4. Chao, M. N.; Lorenzo-Ocampo, M. V; Szajnman, S. H; Rodriguez, J. B; Docampo R. Bioorg. Med. Chem. 2019, 27, 1350.

https://doi.org/10.1016/j.bmc.2019.02.039

5. Wilhelm, E. A.; Jesse, C. R.; Bortolatto, C. F.; Nogueira, C. W.; Savegnago, L. Brain Res. Bull. 2009, 79, 281. 
https://doi.org/10.1016/j.brainresbull.2009.03.006

6. Siesa, H.; Parnham, M. J. Free Radical Biol. Med. 2020, 156, 107. https://doi.org/10.1016/i.freeradbiomed.2020.06.032

7. Miao, Q.; Xu, J.; Lin, A.; Wu, X.; Wu, L.; Xie, W. Curr. Med. Chem. 2018, 25, 2009. https://doi.org/10.2174/0929867325666171129220544

8. Lenardão, E. J.; Santi C.; Sancineto, L. New Frontiers on Organoselenium Compounds. Springer: Cham, Switzerland, 2018.

https://doi.org/10.1007/978-3-319-92405-2

9. Jain, V. K.; Priyadarsini; K. I., Eds. Organoselenium Compounds in Biology and Medicine: Synthesis, Biological and Therapeutic Treatments. Royal Society of Chemistry: London, UK, 2017. https://doi.org/10.1039/9781788011907

10. Santi, C. (Ed.). Organoselenium Chemistry - between Synthesis and Biochemistry. Bentham Science Publishers: Sharjah, U.A.E., 2014.

https://doi.org/10.2174/97816080583891140101

11. Jacob, C.; Giles, G. I.; Giles, N. M.; Sies, H. Angew. Chem. Int. Ed., 2003, 42, 4742. https://doi.org/10.1002/anie.200300573

12. Pacuła, A. J.; Mangiavacchi, F.; Sancineto, L.; Lenardão, E. J.; Ścianowski, J.; Santi, C. Curr. Chem. Biol. 2015, 9, 97-112.

https://doi.org/10.2174/2212796810666160120220725

13. Gutiérrez-Hernández, A. I.; López-Cortés, J. G.; Ortega-Alfaro, M. C.; Ramírez-Apan, M. T.; CázaresMarinero, J. J.; Toscano, R. A. J. Med. Chem. 2012, 55, 4652.

https://doi.org/10.1021/jm300150t

14. Braga, S. S.; Silva, A. M. S. A. Organometallics 2013, 32, 5626. https://doi.org/10.1021/om400446y

15. Deepthi, S. B.; Trivedi, R.; Giribabu, L.; Sujitha, P.; Kumar, C. G. Dalton Trans. 2013, 42, 1180. https://doi.org/10.1039/C2DT31927F

16. Seng, H. L.; Tiekink, E. R. T. Appl. Organometal. Chem. 2012, 26, 655. https://doi.org/10.1002/aoc.2928

17. Taylor, R.; MacCoss, M.; Lawson, A. D. G. J. Med. Chem. 2014, 57, 5841. https://doi.org/10.1021/jm4017625

18. López-Cortés, J. G.; Contreras de la Cruz, L. F.; Ortega-Alfaro, M. C.; Toscano, R. A.; Alvarez-Toledano, C.; Rudler, H. J. Organomet. Chem. 2005, 690, 2229. https://doi.org/10.1016/i.jorganchem.2005.02.022

19. López-Cortés, J. G.; Samano-Galindo, A.; Ortega-Alfaro, M. C.; Toscano, A.; Rudler, H.; Parlier, A.; Alvarez-Toledano, C. J. Organomet. Chem. 2005, 690, 3664.

https://doi.org/10.1016/i.jorganchem.2005.04.034

20. Shimada, K.; Jin, N.; Kawaguchi, M.; Dobashi, K.; Nagano, Y.; Fujimura, M.; Kudoh, E.; Kai, T.; Saito, N.; Masuada, J.; Iwaya, M.; Fujisawa, H.; Aoyagi, S.; Takikawa, Y. Bull. Chem. Soc. Jpn. 1997, 70, 197. https://doi.org/10.1246/bcsj.70.197

21. Ming, G.; Zingaro, R. A. J. Chem. Soc., Perkin Trans. 1 1998, 1, 647.

22. Ishihara, H.; Koketsu, M.; Fukata, Y.; Nada, F. J. Am. Chem. Soc. 2001, 123, 8408. https://doi.org/10.1021/ja005800o

23. Saravanan, V.; Mukherjee, C.; Das, S.; Chandrasekaran, S. Tetrahedron Lett. 2004, 45, 681. https://doi.org/10.1016/i.tetlet.2003.11.067 
24. Shibahara, F.; Sugiura, R.; Murai, T. Org. Lett. 2009, 11, 3064.

https://doi.org/10.1021/ol9010882

25. Bhattacharyya, P.; Woollins J. D. Tetrahedron Lett. 2001, 42, 5949.

https://doi.org/10.1016/S0040-4039(01)01113-3

26 Guoxiong, H.; Fuller, A. L.; Slawin, A. M. Z.; Woollins, J. D. Synlett 2012, 23, 2453.

https://doi.org/10.1055/s-0032-1317310

27 Lage, M. L.; Fernandez, I.; Mancheño. M. J.; Sierra, M. A. Inorg. Chem. 2008, 47, 5253. https://doi.org/10.1021/ic800187r

28 van der Westhuizen, B.; Swarts, P. J.; van Jaarsveld, L. M.; Liles, D. C.; Siegert, U.; Swarts, J. C.; Fernández, I.; Bezuidenhout, D. I. Inorg. Chem. 2013, 52, 6674.

https://doi.org/10.1021/ic4007422

29 Connor, J. A.; Jones, E. M.; Lloyd, J. P. J. Organomet. Chem. 1970, 24, C20.

https://doi.org/10.1016/S0022-328X(00)80254-5

30 Fischer, E. O.; Maasböl, A. Angew. Chem., Int. Ed. Engl. 1964, 3, 580.

https://doi.org/10.1002/anie.196405801

31 Ramírez-Gómez, A.; Gutiérrez-Hernández, A. I.; Alvarado-Castillo, M. A.; Toscano, R. A.; Ortega-Alfaro, M. C.; López-Cortés, J. G. J. Organomet. Chem. 2020, 919, 121315.

https://doi.org/10.1016/i.jorganchem.2020.121315

32 Schobert, R.; Schmalz, T. J. Organomet. Chem. 2004, 689, 1771.

https://doi.org/10.1016/i.jorganchem.2004.02.032

33 Schobert, R.; Kempe, R.; Schmalz, T.; Gmeiner, A. J. Organomet. Chem. 2006, 691, 859.

https://doi.org/10.1016/j.jorganchem.2005.10.047

34 Colthup, N. B.; Daly, L. H.; Wiberley, S. E. Introduction to Infrared and Raman Spectroscopy, Academic Press, 1990.

35 Socrates, G. Infrared and Raman Characteristic Group Frequencies: Tables and Charts, Wiley, 2004.

36 Selenoamides 3(a-g) were obtained with a purity close to 95-99\%, determined by HPLC analyses and the absence of chromium was confirmed by flame atomic absorption spectrometry, using the method described in: May, J. C.; Rain, T. C.; Maienthal, F. J.; Biddle, G. N.; Progar, J. J. J. Biol. Stand. 1986, 14, 363.

37 Crystal data 3f: $\mathrm{C}_{7} \mathrm{H}_{9}$ NOSSe, $\mathrm{M}=234.17$, Monoclinic, $a=8.595(10), b=13.301(15), c=8.139(9) \AA, V$ $=885.7(17) \AA^{3}, T=298 \mathrm{~K}$, space group $P 2_{1} / \mathrm{c}, Z=4, \mu(\mathrm{Mo}-\mathrm{K} \alpha)=4.417 \mathrm{~mm}^{-1}, 5879$ reflections measured, 2026 unique $\left(R_{\text {int }}=0.0202\right)$ which were used in all calculations. The final $R$ and $w R\left(F^{2}\right)$ were 0.0367 and 0.0741 respectively (all data), CCDC 1015044 . These data can be obtained free of charge from The Cambridge Crystallographic Data Centre via www.ccdc.ac.uk/data_request/cif.

38 Laurence, C.; Brameld, K. A.; Graton J.; Le Questel, J. Y.; Renault, E. J. Med. Chem. 2009, 52, 4073. https://doi.org/10.1021/jm801331y

39 Ju, J.; Park, M.; Suk, J.; Lah, M. S.; Jeong, K. S. Chem. Commun. 2008, 3546.

https://doi.org/10.1039/b804284e

40 Kuhn, B.; Mohr, P.; Stahl, M. J. Med. Chem. 2010, 53, 2601.

https://doi.org/10.1021/jm100087s

41 Lalancette, J. M.; Freche, A. Can. J. Chem. 1970, 48, 2367.

https://doi.org/10.1139/v70-395

42 Lalancette, J. M.; Bridle, J. R. Can. J. Chem. 1971, 49, 2990.

https://doi.org/10.1139/v71-498 
43 Monks, A.; Scudiero, D.; Skehan, P.; Shoemaker, R.; Paul, K.; Vistica, D.; Hose, C.; Langley, J.; Cronise, P.; Vaigro-Wolff, A.; Gray-Goodrich, M.; Campbell, H.; Mayo, J.; Boyd, M. J. Natl. Cancer Inst. 1991, 38, 757.

https://doi.org/10.1093/inci/83.11.757

44 Kirtikara, V. V. K. Nature Protocols 2006, 1, 1112.

https://doi.org/10.1038/nprot.2006.179

45 Altomare, A.; Cascarano, G.; Giacovazzo, C.; Guagliardi, A.; Burla, M. C.; Polidori, G.; Canalli, M. J. Appl. Crystallogr. 1994, 27, 435.

https://doi.org/10.1107/S002188989400021X

46 Sheldrick, G. M. Acta Crystallogr. 2008, A64, 112.

https://doi.org/10.1107/S0108767307043930 